\title{
Making measurement results metrologically traceable to SI units requires more than just expressing them in SI units
}

\author{
Paul De Bièvre
}

Published online: 25 February 2010

(C) Springer-Verlag 2010

There is a persistent fallacy in the literature in which "traceability to the SI" is claimed if the measurement result is just reported in SI units.

Traceability is a general ("superordinate") concept, applicable in many fields. One can talk about traceability of a sample of material; thus, identifying its physical origin, or about traceability of a document to its issuing organization (documentary traceability), or certificate (traceability to a responsible signature), and others.

In any measurement context, the most important type of traceability is 'metrological traceability'. It is the traceability of a measurement result to the value embodied inor carried by-a "reference" when obtaining a measurement result for a measurand [1]. This reference can be

- "a definition of a measurement unit through its practical realization" [2],

- "a measurement procedure including the measurement unit for an ordinal quantity" [2], or

- "a measurement standard" [2], such as a "calibrator" [3].

Such metrological traceability can be short and simple such as 'metrological traceability to a measurement unit' [4] which always means to the value of that unit. In most cases, that is the numerical value 1 . If that unit is a (base or derived) unit of the "Système International d'Unités" (well known as the SI), it is customary to talk about "traceability to the SI" [5]. A measurement unit has no measurement uncertainty as it is not measured, but defined.

However, it is not sufficient to name a unit in a measurement result to be metrologically traceable to that unit.

P. De Bièvre $(\square)$

Kasterlee, Belgium

e-mail: paul.de.bievre@skynet.be
The metrological traceability must be to 'a measurement unit through its practical realization' [2] of that measurement unit. In other words, the 'metrological traceability chain' [6] must be established from the (value of the) measurement result to the value embodied in-or carried by-a material,- - or obtained by-a measurement procedure [2].

Thus, metrological traceability to a unit (e.g. an SI unit) implies metrological traceability to a material realization of the definition of that unit.

'Metrological traceability' is not just a simple "statement", it must be based on an unbroken chain of quantity values embodied in a specified material. It must be possible to present a metrological traceability chain, either declared-or at least be presented on request-if the result is to be credible. Just a statement of the unit used, be it an SI unit, is not sufficient.

A visible metrological traceability chain is a key property of any measurement result.

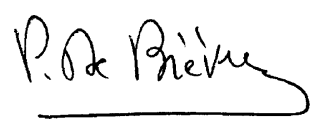

Paul De Bièvre

Editor-in-Chief

P.S. By the way, looking for a justification for MiC?

An error of $1 \%$ in the measurement of the annual amount of natural gas traded in Europe (a commercial value of about $€ 700000000000)$ corresponds to a value of roughly $€ 7000000000$; an error of $0.1 \%$ corresponds to somewhat less than $€ 1000000000$. Taking into account that measurements take place in pipelines and oil storage tanks where one has not only to measure volume but also temperature, pressure and chemical composition, a 
measurement uncertainty of somewhere between 1 and $0.1 \%$ is not likely to be realized.

(R Kaarls, 5th Brasilian Congress of Metrology, Salvador BA, Brazil, 9 November 2009, adjusted later)

\section{References}

1. BIPM, IEC, IFCC, ILAC, ISO, IUPAC, IUPAP, OIML, The International Vocabulary of Metrology - Basic and general concepts and associated terms (VIM), JCGM 200:2008, http://www.bipm.org/en/publications/guides/vim.html, entry 2.3

2. BIPM, IEC, IFCC, ILAC, ISO, IUPAC, IUPAP, OIML (2008) The international vocabulary of metrology - basic and general concepts and associated terms (VIM), JCGM 200:2008. http://www.bipm. org/en/publications/guides/vim.html, entry 2.41 , note 1
3. BIPM, IEC, IFCC, ILAC, ISO, IUPAC, IUPAP, OIML (2008) The international vocabulary of metrology - basic and general concepts and associated terms (VIM), JCGM 200:2008. http://www. bipm.org/en/publications/guides/vim.html, entry 5.12

4. BIPM, IEC, IFCC, ILAC, ISO, IUPAC, IUPAP, OIML (2008) The international vocabulary of metrology - basic and general concepts and associated terms (VIM), JCGM 200:2008. http://www. bipm.org/en/publications/guides/vim.html, entry 2.43

5. BIPM, IEC, IFCC, ILAC, ISO, IUPAC, IUPAP, OIML (2008) The international vocabulary of metrology - basic and general concepts and associated terms (VIM), JCGM 200:2008. http://www. bipm.org/en/publications/guides/vim.html, entry 2.43, note

6. BIPM, IEC, IFCC, ILAC, ISO, IUPAC, IUPAP, OIML (2008) The international vocabulary of metrology - basic and general concepts and associated terms (VIM), JCGM 200:2008. http://www.bipm. org/en/publications/guides/vim.html, entry 2.42 